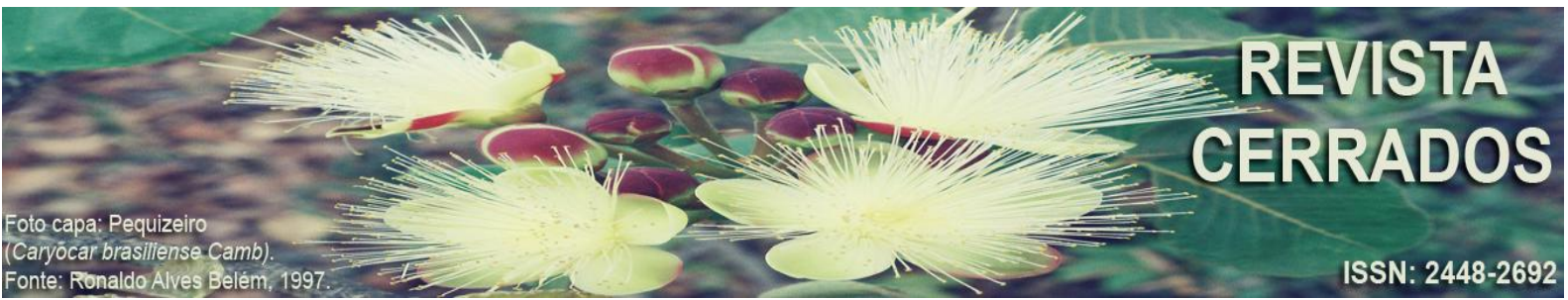

\title{
SUSTENTABILIDADE SOCIOAMBIENTAL, PADRÃO CONSTRUTIVO HABITACIONAL E COMUNIDADES RIBEIRINHAS DO TUPÉ - MANAUS, AMAZONAS
}

\section{SOCIAL AND ENVIRONMENTAL SUSTAINABILITY AND STANDARD HOUSING CONSTRUCTION IN THE TUPÉ RESERVE - MANAUS, AMAZONAS}

\author{
SOSTENIBILIDAD SOCIOAMBIENTAL Y ESTÁNDAR \\ CONSTRUTIVO HABITACIONAL EN LA RESERVA DEL TUPÉ - \\ MANAUS, AMAZONAS
}

\author{
Duarcides Ferreira Mariosa \\ Pontifícia Universidade Católica de Campinas - PUC/Campinas \\ E-mail: <duarcides@gmail.com>. \\ Marcos Ricardo Rosa Georges \\ Pontifícia Universidade Católica de Campinas - PUC/Campinas \\ E-mail: 〈marcos.georges@ puc-campinas.edu.br>. \\ Renato Ribeiro Nogueira Ferraz \\ Universidade Nove de Julho - UNINOVE \\ E-mail: <renatobio@ hotmail.com>. \\ Samuel Carvalho De Benedicto \\ Pontifícia Universidade Católica de Campinas - PUC/Campinas \\ E-mail: 〈samuel.benedicto@puc-campinas.edu.br〉.
}

\section{Resumo}

Com o presente texto objetiva-se identificar os componentes e principais variáveis que compõem o padrão construtivo habitacional na Reserva de Desenvolvimento Sustentável do Tupé (RDS do Tupé) e, numa análise diacrônica, avaliar a pertinência teórico-metodológica deste indicador de sustentabilidade socioambiental. Trata-se de um estudo exploratório, descritivo e de análise ecológica, baseado em pesquisa original de campo, com coleta de dados originais, aplicando-se questionário semi estruturado e técnicas de observação direta. A análise do padrão construtivo habitacional nas comunidades ribeirinhas da RDS do Tupé, examinadas em escala temporal, mostrou que o comportamento das variáveis compositoras do 
indicador utilizado permite a detecção de pontos vulneráveis ou fraquezas sistêmicas capazes de comprometer aspectos econômicos, sociais e ambientais que caracterizam a sustentabilidade daquelas comunidades. Dessa análise, concluiu-se que se o exame do conjunto das variáveis apresenta resultados diversos do exame de cada uma das partes que o compõem, a sustentabilidade socioambiental define-se mais pelo comportamento dos indicadores gerais que dos particulares. Por sua vez, são as modificações observadas nos parâmetros de cada variável que permitem o planejamento e controle dos resultados no longo prazo, validando o uso deste sistema de indicadores como ferramenta de gestão.

Palavras-Chave: Sustentabilidade; Padrão Construtivo; Gestão Ambiental; Unidades de Conservação; Comunidades Ribeirinhas.

\begin{abstract}
The purpose of this article is to identify the components and main variables that make up the Tupé's RDS habitational constructive pattern and, in a diachronic analysis, evaluate the theorical and methodological relevance of this environmental sustainability indicator. This study is explanatory, descriptive and contains ecological analysis, based upon original field research and data collection through a semi structured questionnaire and direct observation techniques. The constructive pattern analysis in the Tupé's RDS riverine communities, in a temporal scale, shows that the variables behavior allows the detection of vulnerable points and systemic weaknesses that may compromise economic, social and environmental aspects that characterize the sustainability of those communities. The conclusion of this analysis is that the assay of the variable set shows different results from the assay of each variable individually; therefore, the socioenvironmental sustainability is defined mainly by the behavior of general indicators, not the particular ones. However, the modifications observed in each variable's parameter are what allow the long term planning and results' control, validating the use of this indicator system as a management tool.
\end{abstract}

Keywords: Sustainability; Constructive pattern; Environmental management; Conservation units; Riverine communities.

\title{
Resumen
}

El presente artículo tiene como objetivo identificar los componentes y principales variables que componen el patrón constructivo habitacional en la Reserva de Desarrollo Sustentable del Tupé (RDS del Tupé) y, en un análisis diacrónico, evaluar la relevancia teórica y metodológica de este indicador de sustentabilidad social y ambiental. Este es un estudio explicativo, descriptivo y de análisis ecológico, basado en la investigación original de campo, con recolección de datos originales, aplicando cuestionarios semi estructurados y técnicas de observación directa. El análisis del patrón constructivo habitacional en las comunidades ribereñas de la RDS del Tupé, examinadas a escala temporal, muestra que el comportamiento de las variables componentes del indicador utilizado permite la detección de puntos vulnerables o debilidades sistémicas capaces de comprometer aspectos económicos, sociales y ambientales que caracterizan la sustentabilidad de esas comunidades. Se concluyó que si el examen del conjunto de las variables presenta resultados diversos del examen de cada una de las partes que lo componen, la sustentabilidad social y ambiental se define más por el comportamiento de los indicadores generales que de los particulares. A su vez, son las 
modificaciones observadas en los parámetros de cada variable las que permiten la planificación y control de los resultados a largo plazo, validando el uso de este sistema de indicadores como herramienta de gestión.

Palabras Clave: Sustenibilidad; Patrón constructivo; Gestión ambiental; Unidades de conservación; Comunidades ribereñas.

\section{INTRODUÇÃO}

A Reserva de Desenvolvimento Sustentável do Tupé (RDS do Tupé) - Manaus, Amazonas, é uma área de preservação ambiental localizada próxima a Manaus, Amazonas, cujos moradores enfrentam dilemas e contradições colocadas, de um lado pela legislação ambiental que, para proteger a rica biodiversidade característica do local, restringe as atividades que ali podem ser desenvolvidas; e, de outro, a proximidade de um centro urbano potencialmente dinâmico e diverso em suas possibilidades econômicas, sociais e culturais. Tal tensão reflete na qualidade de vida dos habitantes e, por isso, na sustentabilidade socioambiental daquelas comunidades.

Indicadores de sustentabilidade (SILVA; CÂNDIDO; RAMALHO, 2012), como os que avaliam o padrão construtivo na RDS do Tupé, resultam de construções intelectuais fundadas nas relações observadas entre sociedade, ambiente e economia, tal como definido na Agenda 2030 para o Desenvolvimento Sustentável (NAÇÕES UNIDAS, 2015). Considera-se que o modo como as pessoas se relacionam - seus padrões de sociabilidade - desenvolve-se a partir de ações e limites definidos em um quadro multidimensional e de instituições de grande complexidade (WAIZBORT; SIMMEL, 2002). Na vida concreta, as práticas coletivas - como as concernentes à educação, saúde trabalho, comprometimento, participação e organização política -, interagem com as condições oferecidas pela paisagem geográfica e os recursos simbólicos, políticos e econômicos nela presentes. O espaço onde o indivíduo vive e trabalha, sua renda, o acesso aos bens públicos de cidadania e as condições de conforto e habitabilidade de sua moradia formam uma totalidade cujas fronteiras nem sempre são claras e precisas, mas que determina, condiciona ou impacta, de alguma forma e em maior ou menor grau, a qualidade de suas condições de vida e existência (SANTOS; MARQUES; DUARTE, 2011).

As condições de habitabilidade (Figura 1) envolvem desde as técnicas utilizadas na edificação, especificidades dos materiais empregados e do estilo construtivo, até a forma 
como se dão as trocas ambientais - dentre as quais o abastecimento de água potável e o destino dado ao esgoto, lixo e outros resíduos -, e energéticas, como eletricidade, combustíveis para uso domiciliar e transporte que demanda (SILVA; CÂNDIDO; RAMALHO, 2012). Há um sentido, uma qualidade ou tipo de percepção que perpassa as moradias e configura sua identidade grupal. São as marcas estabelecidas com o entorno e que estão presentes em cada casa, edifício ou unidade de moradia. Trata-se das formas e representações, ornamentos, adereços, equipamentos e espaços que ocupam, além dos detalhes que carregam do universo de sentimentos, vivências, tradições e experiências de seus ocupantes; materializadas, neste estudo, no padrão construtivo das comunidades ribeirinhas da RDS do Tupé (STELLA, 2008).

Figura 1 - Diagrama de variáveis do componente Habitabilidade para fins de cálculo do IQSA

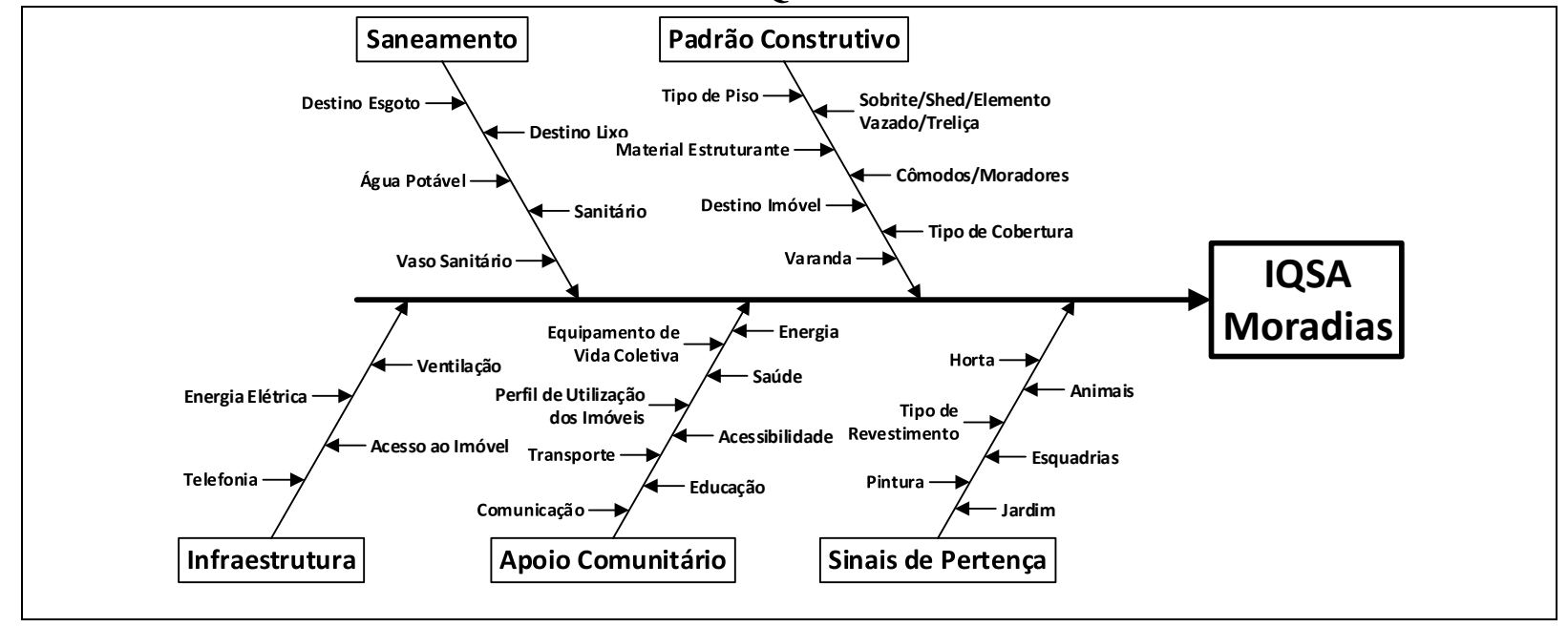

Fonte: Elaborada pelos autores, com base em Santos-Silva, Scudeller e Cavalcanti (2011).

No sentido que aqui se propõe adotar, habitabilidade são as marcas, sinais ou o conjunto de traços inscritos nas construções, nos materiais preferencialmente utilizados, suas linhas, contornos e desenhos, nos acessórios, adornos e adereços que as completam, e a totalidade dos equipamentos e espaços que ocupam um universo simbólico, carregado dos sentimentos, vivências e experiências de seus ocupantes (BOURDIEU, 1983; SILVA, 2000). Transcende, portanto, o que pode ser considerado como simples objetos ou coisas. Tomadas individualmente, as construções deixam de ser apenas "casa", "residência" ou local de moradia para se transformar em "lar", espaço privilegiado das relações primárias da unidade familiar. Do mesmo modo, prédios comerciais, edifícios do governo e demais espaços 
MARIOSA, D. F.; GEORGES, M. R. R.; FERRAZ, R. R. N.; BENEDICTO, S. C.

Sustentabilidade socioambiental, padrão construtivo habitacional e comunidades Ribeirinhas do Tupé - Manaus, Amazonas

coletivos deixam de ser meras peças de arquitetura para se transformarem em bares, escolas, posto de saúde, igrejas e pontos de encontro e interação de pessoas.

A habitabilidade vista conceitualmente sob uma abordagem ecológica ou sistêmica de análise não rejeita ou exclui a necessária influência dos indivíduos. São eles quem decidem permanecer num mesmo local, ligados a determinados grupos, exercendo atividades as mais diversas se ali encontrarem respaldo para os seus mais profundos e necessários anseios existenciais. São eles quem transformam, por suas ações, a realidade que encontram. Nisto consiste a estabilidade de todo o sistema, sua sustentabilidade (BRAUN, 2001).

Sachs (2000) fala de oito dimensões da sustentabilidade. São elas: a social, envolvendo fatores contribuintes da homogeneidade entre os participantes da vida coletiva, como a distribuição de renda justa, qualidade de vida e igualdade no acesso aos recursos e serviços sociais; a cultural, referente aos processos endógenos de mudanças, continuidade e equilíbrio entre tradição e inovação; a ecológica, que reflete a preservação do capital natural e o incentivo ao uso de recursos renováveis; a ambiental, presente no respeito à capacidade de regeneração dos ecossistemas naturais; a territorial, que encontra e produz equilíbrio entre o rural e o urbano e supera disparidades inter e intra-regionais; a econômica, que mantém o desenvolvimento econômico intersetorial equilibrado e a capacidade de modernização contínua dos instrumentos de produção, autonomia na pesquisa científica e tecnológica, e inserção soberana na economia internacional; a política nacional, fundada em valores democráticos, apropriação universal dos direitos humanos e no desenvolvimento da capacidade do Estado em mobilizar recursos e os mais diferentes setores da sociedade num projeto nacional; a política internacional, cuja preocupação é com a paz, cooperação e garantia dos direitos individuais, coletivos e da herança comum da humanidade.

Nascimento (2012), por sua vez, enumera três dessas dimensões da sustentabilidade. A primeira é a ambiental, ou seja, produzir e consumir de forma a garantir que os ecossistemas possam manter sua autorreparação ou capacidade de resiliência. A segunda é a econômica, que supõe uma contínua inovação tecnológica, que leve à saída do ciclo fóssil de energia (carvão, petróleo e gás) e à ampliação da desmaterialização da economia. A terceira é a social, cuja dimensão atende o objetivo de erradicar a pobreza e definir um padrão de desigualdade aceitável, delimitando limites mínimos e máximos de acesso a bens materiais. 
MARIOSA, D. F.; GEORGES, M. R. R.; FERRAZ, R. R. N.; BENEDICTO, S. C.

Sustentabilidade socioambiental, padrão construtivo habitacional e comunidades Ribeirinhas do Tupé - Manaus, Amazonas

O conceito de habitabilidade adotado neste estudo emerge da relação observada entre casas e moradias, comunidade e moradores mediante, entre outras possibilidades de análise, o estudo do padrão construtivo das unidades habitacionais.

Nesta perspectiva, moradia é o imóvel usado como domicílio ou residência, edificado estruturalmente de modo a, de um lado, manter isolados seus moradores de inconvenientes externos, utilizando paredes, muros, cercas e teto, adaptando o elemento humano ao entorno social e ambiental; e, de outro, a permitir que ali possam ser garantidas as condições de conforto, higiene, repouso e demais atividades relacionadas à sociabilidade humana. Não se considera como moradia, portanto, os prédios, edifícios e construções que possuam fins público, comercial, administrativo e de uso coletivo; casas de veraneio; espaços de lazer; escolas e templos religiosos, embora estes sejam fundamentais na configuração de espaços de apoio comunitário (IBGE, 2011).

Comunidade é a unidade socioterritorial resultante da interação e proximidade relativa de várias unidades de moradia. Não é apenas o espaço físico marcado pela presença de moradias, prédios e construções de uso coletivo, espaços comunitários, arruamentos, praças, cursos d'água, campos, sítios e unidades de plantio, mas a unidade de convivência que, como tal, é reconhecida por seus ocupantes e por aqueles que as visitam ou observam. Nas comunidades é que estão presentes fenômenos de natureza sociocultural, como os laços de pertencimento vividos pelos moradores (AMARAL et al., 2013).

Moradores são aqueles que utilizam a moradia como local de residência habitual. Refere-se à população fixa do local, não se considerando moradores temporários, veranistas, ambulantes, turistas e outros que frequentam as comunidades investigadas somente para o exercício de suas funções profissionais (IBGE, 2011).

Colocados no mesmo espaço socioterritorial, moradores, moradias e comunidades formam uma realidade ecológica de natureza complexa, derivados de inúmeros componentes (NEVES; NEVES, 2006). Não é uma variável isolada, como o ambiente físico, geográfico ou biológico, que determina os comportamentos, mas, especialmente e de modo singular, o conjunto das atividades que são desenvolvidas nestes espaços. $\mathrm{O}$ ambiente das relações sociais influencia comportamentos individuais por meio de mecanismos coletivos, como: (i) a orientação cultural que estabelece normas e regras sociais; (ii) as formas de controle social, dizendo o que é e o que não é aceito, conveniente ou adequado; (iii) a criação ou legitimação de ambientes oportunos ou não para a prática de determinadas atividades ou comportamentos, 
MARIOSA, D. F.; GEORGES, M. R. R.; FERRAZ, R. R. N.; BENEDICTO, S. C.

Sustentabilidade socioambiental, padrão construtivo habitacional e comunidades Ribeirinhas do Tupé - Manaus, Amazonas

e; (iv) a redução ou ampliação do stress para que certo comportamento possa ser copiado ou reproduzido (BERKMAN; KAWACHI; GLYMOUR, 2014; GONÇALVES, 2004).

Sociedades humanas são igualmente sistemas sociais. Como tal, sua sustentabilidade é passível de aferição, mediante a construção de indicadores selecionados com base no comportamento das variáveis que compõem os diversos níveis de interação ou dimensões sistêmicas da ação social (MONTEIRO, 2010). Indicadores não possuem um significado que se esgota nele mesmo e, por seu intermédio, torna-se possível inferir padrões, referências, quadros quantitativa ou qualitativamente elaborados para a apreensão da influência de dada circunstância. É por essa razão que indicadores de sustentabilidade permitem diferentes arranjos conceituais entre suas variáveis componentes (BELLEN, 2008).

Enquanto construto intelectual, de natureza numérica ou abstrata, permite realizar comparações. Ao se comparar padrões obtidos das mesmas variáveis e nas mesmas circunstâncias de coleta, porém em momentos distintos, tem-se a medida do comportamento das variáveis estudadas. Na hipótese de ocorrência de inúmeras ações, sejam individuais ou coletivas, internas ou externas ao grupo, realizadas de forma intencional ou não, os efeitos descritos na comparação apontam para uma situação que pode ser de estabilidade (sustentabilidade) ou de desestabilização (insustentabilidade) da realidade socioambiental estudada (JANNUZZI, 2016).

Admitindo-se, neste estudo, que sustentabilidade é uma condição do sistema, ou seja, que a interação complexa de suas partes constituintes produz uma realidade que se coloca além da simples soma de tais partes, qualquer variabilidade encontrada, em qualquer de suas partes, é passível de constituir-se em fator de quebra das condições de sustentabilidade (SILVA; CÂNDIDO; RAMALHO, 2012). Daí a importância e viabilidade de se analisar o padrão construtivo como indicador da sustentabilidade socioambiental das comunidades ribeirinhas da RDS do Tupé. Observá-las, nesta perspectiva, é algo intelectualmente instigante e que por si só já justifica e legitima os estudos realizados. Porém, padrões construtivos analisados também em escala temporal permitem identificar inconsistências e vulnerabilidades sistêmicas e estruturais.

Como ferramenta de gestão, indicadores apontam com maior precisão e acurácia para medidas tópicas e pontuais que agentes públicos, lideranças comunitárias e moradores possam desenvolver na direção do viver com mais conforto e desfrutar de uma melhor qualidade de vida nas comunidades. Tal é o objetivo do presente estudo: identificar os 
componentes e principais variáveis que compõem o item padrão construtivo na RDS do Tupé e, comparando os dados encontrados em dois momentos no tempo, avaliar a pertinência teórico-metodológica deste indicador de sustentabilidade socioambiental.

\section{PROCEDIMENTOS METODOLÓGICOS}

Trata-se o presente texto de um estudo observacional, descritivo (PEREIRA, 2014) e de análise ecológica (PETERSEN et al., 2017), baseado em pesquisa de campo com coleta de dados originais das moradias, prédios e construções das comunidades ribeirinhas da RDS do Tupé, mediante aplicação de questionários estruturados e de observação direta.

A área de estudo localiza-se na Amazônia brasileira. Localizada à margem esquerda do Rio Negro, a RDS do Tupé (Figura 2) é uma área de proteção ambiental situada na zona rural de Manaus. Possui 12.000 hectares de extensão, e abriga em torno de 1.800 moradores fixos no interior de seus limites, distribuídos em seis comunidades, sendo cinco ribeirinhas (Tatulândia, São João do Tupé, Julião, Livramento e Agrovila) e uma de assentamento rural (Central). Neste estudo são analisadas apenas as comunidades ribeirinhas da RDS do Tupé, pois que partilham da mesma influência do ritmo das águas em seu modo de vida, criando, dessa forma, condições semelhantes para a construção de uma identidade coletiva ou com poucas variações em suas representações sociais (SERRA, 2002).

\section{Figura 2 - Comunidades da Reserva de Desenvolvimento Sustentável do Tupé, Manaus,} Amazonas

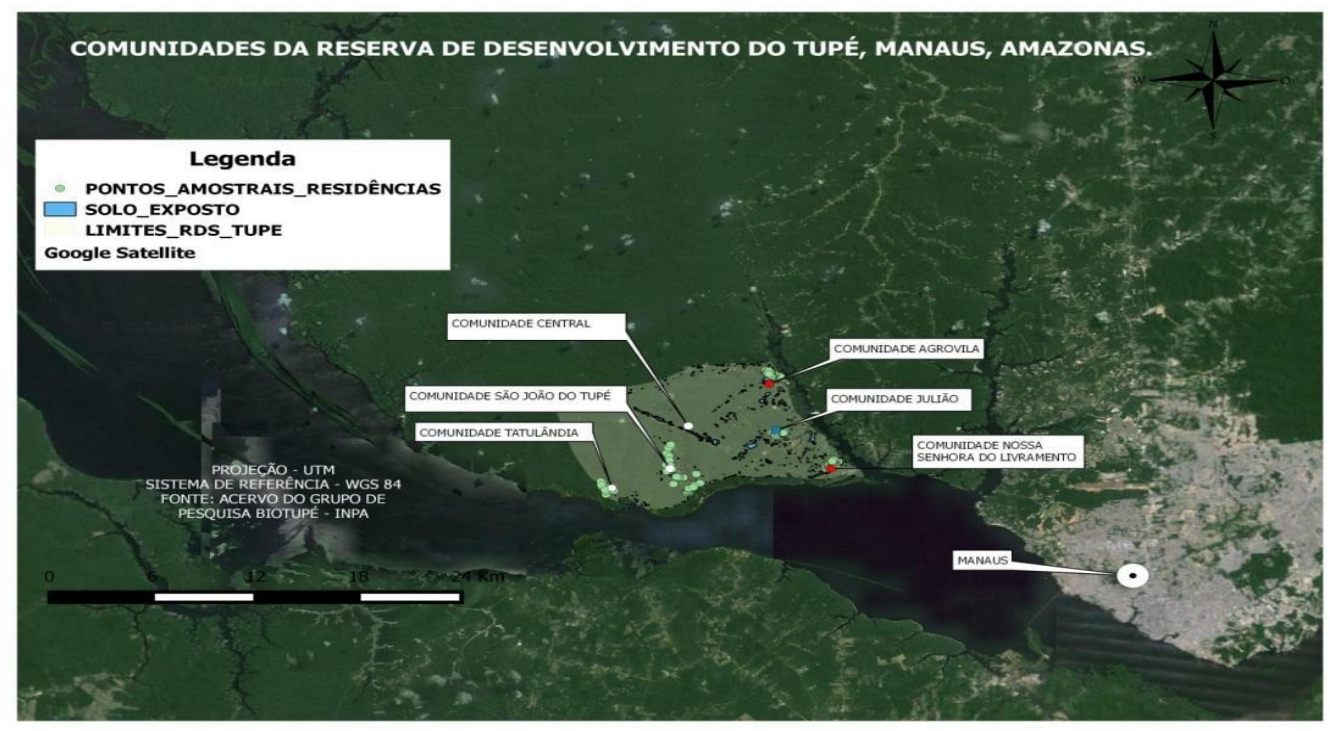


MARIOSA, D. F.; GEORGES, M. R. R.; FERRAZ, R. R. N.; BENEDICTO, S. C.

Sustentabilidade socioambiental, padrão construtivo habitacional e comunidades Ribeirinhas do Tupé - Manaus, Amazonas

Fonte: Elaborado pelos autores, com base em dados coletados em pesquisa de campo realizada em 2013.

O objeto de estudo é o padrão construtivo das comunidades ribeirinhas da RDS do Tupé que, mediante a análise dos componentes estruturantes das construções, edifícios, casas, espaços de convívio e locais de moradia construídos no local, selecionados como adiante descrito, pretende examinar a qualidade da relação sociedade e ambiente e, com isso, estabelecer a viabilidade da aplicação de indicadores de sustentabilidade em áreas de proteção ambiental.

O plano amostral foi delineado a partir da distribuição espacial das construções localizadas nas comunidades Tatulândia, São João do Tupé, Agrovila, Julião e Livramento. Por se tratar de um número pequeno de unidades e concentrados nas áreas centrais das comunidades, os dados foram coletados de forma censitária, mediante levantamento de campo realizado, primeiramente, entre os meses de janeiro e fevereiro de 2009 e, num segundo momento, nos meses de janeiro e fevereiro de 2013, no âmbito dos estudos de indicadores de qualidade socioambiental e nas mesmas comunidades (MARIOSA et al., 2014). A coleta de dados ocorreu mediante aplicação de questionários estruturados e entrevistas com os moradores (realizadas por equipes orientadas e treinadas para o contato com os informantes), por apresentação e assinatura dos termos de consentimento livre e esclarecido, e pelo adequado preenchimento das respostas.

Para a montagem das tabelas e construção dos indicadores de cada uma das variáveis, as notas dadas a cada quesito foi multiplicada pelo número de ocorrências encontradas entre as comunidades da RDS do Tupé e pela nota constante do Quadro 1. Na interpretação dos dados seguiu-se o modelo ecológico, procurando por evidências de associação entre as variáveis e com as situações observadas diretamente nas comunidades. $\mathrm{Na}$ elaboração do Indicador de Qualidade SocioAmbiental das Moradias (IQSA), representativo das condições de habitabilidade das comunidades. Cada variável que compõem o padrão construtivo investigado recebeu uma "nota" ou "peso", considerando-se sua aproximação ou distanciamento aos padrões de conformidade tipológica recomendados na bibliografia consultada para o tipo de clima, solo, vegetação, das características de seu uso e ocupação, e das necessidades de preservação ambiental. Em razão da especificidade do local considerado - comunidades ribeirinhas situadas em área de reserva de desenvolvimento sustentável adotou-se como critério de avaliação que as condições mais adequadas de cada variável 
teriam peso "10", as totalmente inadequadas ou inexistentes receberiam peso " 0 ", e as intermediárias “2”, “4”, “6” ou "8”.

\section{Quadro 1 - Variáveis componentes do "padrão construtivo", encontradas nas moradias examinadas na RDS do Tupé, Manaus, Amazonas (2009)}

\begin{tabular}{|c|c|c|}
\hline & & Informação contida \\
\hline Variável & Descrição & $\begin{array}{l}\text { Peso relativo das respostas às } \\
\text { variáveis: ótimo (10); bom (8); } \\
\text { médio (6); regular (4); péssimo } \\
\text { (2), ou inexistente (0) }\end{array}$ \\
\hline \multirow{5}{*}{$\begin{array}{l}\text { Destino dado ao } \\
\text { imóvel }\end{array}$} & \multirow{5}{*}{ Qual emprego ou função tem a construção } & residência $(10)$ \\
\hline & & uso coletivo (8) \\
\hline & & estatal $(6)$ \\
\hline & & comércio (4) \\
\hline & & outro (2) \\
\hline \multirow{5}{*}{ Material estruturante } & \multirow{5}{*}{$\begin{array}{l}\text { Tipo de construção segundo o material empregado } \\
\text { na edificação }\end{array}$} & mista (alvenaria e madeira) (10) \\
\hline & & alvenaria (8) \\
\hline & & madeira (6) \\
\hline & & palha/lona (4) \\
\hline & & outro $(2)$ \\
\hline \multirow{5}{*}{ Tipo de cobertura } & \multirow{5}{*}{$\begin{array}{l}\text { Material empregado no telhamento das } \\
\text { construções }\end{array}$} & telha de barro (10) \\
\hline & & palha (8) \\
\hline & & fibrocimento (6) \\
\hline & & zinco $(4)$ \\
\hline & & outro (2) \\
\hline \multirow{5}{*}{ Número de cômodos } & \multirow{5}{*}{ Divisão interna do imóvel } & $\geq 5(10)$ \\
\hline & & $4(8)$ \\
\hline & & $3(6)$ \\
\hline & & $2(4)$ \\
\hline & & $1(2)$ \\
\hline \multirow{5}{*}{$\begin{array}{l}\text { Número de } \\
\text { moradores }\end{array}$} & \multirow{5}{*}{ Número de moradores fixos do imóvel } & $\geq 5(10)$ \\
\hline & & $4(8)$ \\
\hline & & $3(6)$ \\
\hline & & $2(4)$ \\
\hline & & $1(2)$ \\
\hline \multirow{5}{*}{$\begin{array}{l}\text { Moradores por } \\
\text { cômodo }\end{array}$} & \multirow{5}{*}{$\begin{array}{l}\text { Proporção entre o número de moradores por } \\
\text { cômodo existente na residência }\end{array}$} & $<1(10)$ \\
\hline & & $=1(8)$ \\
\hline & & $>1(6)$ \\
\hline & & $>2(4)$ \\
\hline & & $>3(2)$ \\
\hline \multirow{5}{*}{ Tipo de piso } & \multirow{5}{*}{$\begin{array}{l}\text { Revestimento empregado na imperabilização das } \\
\text { superfícies internas das construções }\end{array}$} & cerâmico (10) \\
\hline & & cimentado (8) \\
\hline & & madeira (6) \\
\hline & & chão batido (4) \\
\hline & & outro (2) \\
\hline \multirow{2}{*}{ Varanda } & \multirow{2}{*}{$\begin{array}{l}\text { Área coberta ao redor do imóvel para } \\
\text { sombreamento }\end{array}$} & $\operatorname{sim}(10)$ \\
\hline & & não (0) \\
\hline \multirow{2}{*}{$\begin{array}{l}\text { Conforto térmico - } \\
\text { treliças }\end{array}$} & \multirow{2}{*}{$\begin{array}{l}\text { Uso de perfis de madeira entrelaçados com } \\
\text { abertura central para circulação de ar }\end{array}$} & $\operatorname{sim}(10)$ \\
\hline & & não (0) \\
\hline \multirow{2}{*}{$\begin{array}{l}\text { Conforto térmico - } \\
\text { elemento vazado }\end{array}$} & \multirow{2}{*}{$\begin{array}{l}\text { Uso de peças de cerâmica que facilita a circulação } \\
\text { de ar ou reduz a temperatura ambiente }\end{array}$} & $\operatorname{sim}(10)$ \\
\hline & & não $(0)$ \\
\hline \multirow{2}{*}{$\begin{array}{l}\text { Conforto térmico - } \\
\text { shed }\end{array}$} & \multirow{2}{*}{$\begin{array}{c}\text { Tipo de abertura na cobertura que facilita a } \\
\text { ventilação e dissipação do ar quente interno às } \\
\text { construções }\end{array}$} & $\operatorname{sim}(10)$ \\
\hline & & não (0) \\
\hline \multirow{2}{*}{$\begin{array}{l}\text { Conforto térmico - } \\
\text { sombrite }\end{array}$} & \multirow{2}{*}{$\begin{array}{l}\text { Uso de telas escuras que facilita a circulação de ar } \\
\text { ou reduz a temperatura ambiente }\end{array}$} & $\operatorname{sim}(10)$ \\
\hline & & não (0) \\
\hline
\end{tabular}

Fonte: Elaborado pelos autores a partir dos dados da pesquisa realizada. 
Para o cálculo construtivo da variável padrão considerou-se, neste estudo, o conjunto de procedimentos, técnicas e recursos construtivos que as comunidades ribeirinhas da RDS do Tupé costumam adotar em relação à estrutura física dos imóveis, sua adaptabilidade às condições climáticas e demais fatores ambientais, conforto térmico e espacial, durabilidade e resistência dos materiais empregados. Resulta da soma ponderada das seguintes variáveis, cujos pesos atribuídos estão entre parênteses:

1. Destino do imóvel. Considerando-se que a particularidade principal da RDS do Tupé é a de constituir-se legalmente numa área de proteção ambiental, os pesos foram atribuídos em conformidade com o emprego ou função ambientalmente adequado que a construção possui: residência (10); uso coletivo (8); estatal (6); comércio (4); outro (2).

2. Material estruturante. Avalia-se que o material empregado na construção dos edifícios pode ser mais ou menos impactante ao ambiente e melhor adaptado às condições climáticas, conforme o seguinte peso e tipologia: mista de alvenaria e madeira (10); alvenaria (8); madeira (6); palha ou lona (4); outro (2).

3. Tipo de cobertura. Os materiais empregados na cobertura ou telhamento das construções possuem características de conforto térmico e impacto ambiental que, somadas, foram usadas para estabelecer os critérios de hierarquização das opções encontradas na RDS do Tupé: barro (10); palha (8); fibrocimento (6); zinco (4); outro (2).

4. Número de Moradores. Trata-se da quantia de moradores fixos que mantém residência no imóvel investigado. O pressuposto de hierarquização é que quanto maior for o número de indivíduos, maior será a rede de apoio e suporte social, onde há a seguinte classificação: 1 morador (2); 2 moradores (4); 3 moradores (6); 4 moradores (8); 5 moradores ou mais (10).

5. Número de Cômodos. Considera-se, para efeito de ponderação, que quanto mais peças contém as unidades de moradia, maior conforto poderá oferecer a seus ocupantes. Dessa forma e considerando-se os casos de maior ocorrência levantados nas comunidades, tem-se a seguinte distribuição de pesos: 1 cômodo (2); 2 cômodos (4); 3 cômodos (6); 4 cômodos (8); 5 cômodos ou mais (10).

6. Moradores por cômodo. Entende-se a proporção calculada: primeiro dividindo-se a totalização da variável número de moradores pela soma do número de moradores encontrados; em seguida, repetindo-se este mesmo processo em relação à variável número de cômodos e sua totalização; finalmente dividindo-se o coeficiente dos moradores pelo 
coeficiente dos cômodos e a este resultado atribuindo-se os seguintes pesos: $<1(10) ;=1$ $(8) ;>1(6) ;>2(4) ;>3(2)$.

7. Tipo de Piso. O tipo de revestimento empregado na impermeabilização das superfícies internas das construções permite maior ou menor isolamento térmico, segurança e conforto aos moradores. Considera-se, neste estudo, a seguinte classificação: cerâmica (10); cimentado (8); madeira (6); chão batido (4); outro (2).

8. As opções construtivas para arrefecer as altas temperaturas proporcionadas pelo clima amazônico foram distribuídas, neste estudo, em 05 grandes categorias, e ordenadas apenas em duas possibilidades, se existem (10) ou não (0) no imóvel avaliado os seguintes recursos construtivos:

8.1. Sombrite. Telas usadas para proteção e sombreamento;

8.2. Shed. Estruturas moldadas na cobertura, para facilitar a iluminação e ventilação.

8.3. Treliças. Estruturas reticuladas, geralmente de madeira ou palha trançada, colocadas em volta das construções para facilitar a circulação de ar e redução da luminosidade e calor;

8.4. Elemento Vazado. Blocos, tijolos ou peças de cerâmica, vidro, concreto ou madeira não totalmente inteiriços, mas "vazados", formando desenhos os mais diversos, que além de função decorativa nas paredes, permitem a passagem controlada de luz e ar;

8.5. Varanda. Extensões cobertas construídas à volta das casas, de paredes externas abertas ou parcialmente fechadas, cuja principal função é criar uma zona de transição entre o exterior e o interior das residências.

\section{O PADRÃO CONSTRUTIVO NA RDS DO TUPÉ}

A coleta de dados que originou este estudo ocorreu em dois momentos subsequentes e nas mesmas comunidades ribeirinhas da RDS do Tupé. Nos meses de janeiro a dezembro de 2009, 579 edificações foram observadas e os dados que compõem o padrão construtivo anotados e sumarizados na Tabela 1. Repetindo-se o mesmo procedimento, no período de janeiro a fevereiro de 2013, os dados sumarizados das 555 edificações são os constantes da Tabela 2. 
MARIOSA, D. F.; GEORGES, M. R. R.; FERRAZ, R. R. N.; BENEDICTO, S. C.

Sustentabilidade socioambiental, padrão construtivo habitacional e comunidades Ribeirinhas do Tupé - Manaus,

Amazonas

Tabela 1 - Demonstrativo de cálculo - IQSA Moradias - Padrão construtivo da RDS Tupé (2009)

\begin{tabular}{|c|c|c|c|c|c|c|c|}
\hline \multirow{2}{*}{ Destino Imovel } & residência & uso coletivo & estatal & comércio & outro & não informado & TOTAL \\
\hline & 465 & 44 & 9 & 33 & 14 & 14 & \multirow{3}{*}{5216} \\
\hline Peso Aplicado & 10 & 8 & 6 & 4 & 2 & 0 & \\
\hline Sub - Total & 4650 & 352 & 54 & 132 & 28 & 0 & \\
\hline \multirow{2}{*}{ Tipo Construção } & mista & alvenaria & madeira & palha/lona & outro & não informado & \\
\hline & 107 & 69 & 372 & 4 & 2 & 25 & \multirow{3}{*}{3874} \\
\hline Peso Aplicado & 10 & 8 & 6 & 4 & 2 & 0 & \\
\hline Sub - Total & 1070 & 552 & 2232 & 16 & 4 & 0 & \\
\hline \multirow{2}{*}{ Tipo Cobertura } & telha de barro & palha & fibrocimento & zinco & outro & não informado & \\
\hline & 12 & 13 & 322 & 183 & 8 & 41 & \multirow{3}{*}{1904} \\
\hline Peso Aplicado & 10 & 8 & 6 & 4 & 2 & 0 & \\
\hline Sub - Total & 120 & 104 & 932 & 732 & 16 & 0 & \\
\hline \multirow{2}{*}{ Número de Cômodos } & 1 & 2 & 3 & 4 & 5 ou mais & não informado & \\
\hline & 99 & 91 & 92 & 61 & 45 & 191 & \multirow{3}{*}{2052} \\
\hline Peso Aplicado & 2 & 4 & 6 & 8 & 10 & 0 & \\
\hline Sub - Total & 198 & 364 & 552 & 488 & 450 & 0 & \\
\hline \multirow{2}{*}{ Número de Moradores } & 1 & 2 & 3 & 4 & 5 ou mais & não informado & \\
\hline & 32 & 35 & 41 & 33 & 53 & 385 & \multirow{3}{*}{1244} \\
\hline Peso Aplicado & 2 & 4 & 6 & 8 & 10 & 0 & \\
\hline Sub - Total & 64 & 140 & 246 & 264 & 530 & 0 & \\
\hline \multirow{2}{*}{ Moradores por cômodo } & Cômodos & Moradores & \begin{tabular}{|l|} 
Média \\
\end{tabular} & \begin{tabular}{|l|} 
Coeficiente \\
\end{tabular} & Proporção & & \\
\hline & 2052 & 1244 & Moradores p/ & \begin{tabular}{|l|l}
1,212 \\
\end{tabular} & \begin{tabular}{|l|}
6 \\
\end{tabular} & & \multirow{3}{*}{2790} \\
\hline Imoveis & 388 & 194 & Cômodos & & 465 & & \\
\hline & 5,288 & 6,412 & 1,212 & & 2790 & & \\
\hline \multirow{2}{*}{ Tipo de piso } & cerâmico & cimentado & madeira & chão batido & outro & não informado & \\
\hline & 36 & 102 & 174 & \begin{tabular}{|l|}
36 \\
\end{tabular} & 1 & 230 & \multirow{3}{*}{2366} \\
\hline Peso Aplicado & 10 & 8 & 6 & 4 & 2 & 0 & \\
\hline Sub - Total & 360 & 816 & 1044 & 144 & 2 & 0 & \\
\hline \multirow{2}{*}{ Varanda } & $\sin$ & não & não informado & & & & \\
\hline & 178 & 158 & 243 & & & & \multirow{3}{*}{1780} \\
\hline Peso Aplicado & 10 & 0 & 0 & & & & \\
\hline Sub - Total & 1780 & 0 & 0 & & & & \\
\hline \multirow{2}{*}{ Conforto térmico: Treliças } & $\operatorname{sim}$ & não & não informado & & & & \\
\hline & 35 & 279 & 265 & & & & \multirow{3}{*}{350} \\
\hline Peso Aplicado & 10 & 0 & 0 & & & & \\
\hline Sub - Total & 350 & 0 & 0 & & & & \\
\hline \multirow{2}{*}{ Conforto térmico: Elemento Vazado } & $\sin$ & กão & não informado & & & & \\
\hline & 18 & 292 & 269 & & & & \\
\hline Peso Aplicado & 10 & 0 & 0 & & & & 180 \\
\hline Sub - Total & 180 & 0 & 0 & & & & \\
\hline Conforto térmico: Shed & $\sin$ & não & não informado & & & & \\
\hline & 6 & 305 & 268 & & & & \\
\hline Peso Aplicado & 10 & 0 & 0 & & & & 60 \\
\hline Sub - Total & 60 & 0 & 0 & & & & \\
\hline Conforto térmico: Sombrite & $\sin$ & não & não informado & & & & \\
\hline Conforto termico: Sombrite & 5 & 303 & 271 & & & & \\
\hline Peso Aplicado & 10 & 0 & 0 & & & & 50 \\
\hline Sub - Total & 50 & 0 & 0 & & & & \\
\hline TOTAL & & & & & & & 21866 \\
\hline & 12 VARI & IAVEIS & & & & & \\
\hline $\begin{array}{l}\text { TQSA MORADLAS - PAWRAO CONSIRUIIVO- } \\
\text { PONDERACÃO } 0 \text { A } 1\end{array}$ & 579 EDIFI & CAÇÕES & & $21866 / 6$ & 69480 & & 0,314 \\
\hline & 69480 PONTO & S POSSIVEIS & & & & & \\
\hline
\end{tabular}

Fonte: Elaborada pelos autores, com base nos dados coletado sem Janeiro/Fevereiro de 2009. 
MARIOSA, D. F.; GEORGES, M. R. R.; FERRAZ, R. R. N.; BENEDICTO, S. C.

Sustentabilidade socioambiental, padrão construtivo habitacional e comunidades Ribeirinhas do Tupé - Manaus,

\section{Amazonas}

\section{Tabela 2 - Demonstrativo de cálculo - IQSA Moradias - Padrão construtivo da RDS Tupé (2013)}

\begin{tabular}{|c|c|c|c|c|c|c|c|}
\hline \multirow{2}{*}{ Destino Imovel } & residência & uso coletivo & estatal & comércio & outro & não informado & TOTAL \\
\hline & 413 & 45 & 7 & 39 & 14 & 37 & \multirow{3}{*}{4716} \\
\hline Peso Aplicado & 10 & 8 & 6 & 4 & 2 & 0 & \\
\hline Sub - Total & 4130 & 360 & 42 & 156 & 28 & 0 & \\
\hline \multirow{2}{*}{ Tipo Construção } & mista & alvenaria & madeira & palha/lona & outro & não informado & \\
\hline & 116 & 92 & 321 & 3 & 4 & 19 & \multirow{3}{*}{3842} \\
\hline Peso Aplicado & 10 & 8 & 6 & 4 & 2 & 0 & \\
\hline Sub - Total & 1160 & 736 & 1926 & 12 & 8 & 0 & \\
\hline \multirow{2}{*}{ Tipo Cobertura } & telha de barro & palha & fibrocimento & zinco & outro & não informado & \\
\hline & 11 & 8 & 317 & 185 & 5 & 29 & \multirow{3}{*}{2826} \\
\hline Peso Aplicado & 10 & 8 & 6 & 4 & 2 & 0 & \\
\hline Sub - Total & 110 & 64 & 1902 & 740 & 10 & 0 & \\
\hline \multirow{2}{*}{ Número de Cômodos } & 1 & 2 & 3 & 4 & 5 ou mais & não informado & \multirow{4}{*}{1312} \\
\hline & 53 & 38 & 58 & 52 & 29 & 325 & \\
\hline Peso Aplicado & 2 & 4 & 6 & 8 & 10 & 0 & \\
\hline Sub - Total & 106 & 152 & 348 & 416 & 290 & 0 & \\
\hline \multirow{2}{*}{ Número de Moradores } & 1 & 2 & 3 & 4 & 5 ou mais & não informado & \\
\hline & 21 & 33 & 25 & 24 & 49 & 403 & \multirow{3}{*}{1006} \\
\hline Peso Aplicado & 2 & 4 & 6 & 8 & 10 & 0 & \\
\hline Sub - Total & 42 & 132 & 150 & 192 & 490 & 0 & \\
\hline \multirow{2}{*}{ Moradores por cômodo } & Cômodos & Moradores & Média & Coeficiente & Proporção & & \\
\hline & 1312 & 1006 & Moradores $\mathrm{p} /$ & 0,859 & 10 & & \multirow{3}{*}{4130} \\
\hline Peso Aplicado & 230 & 152 & Cômodos & & 413 & & \\
\hline Sub - Total & 7,704 & 6,618 & 0,859 & & 4130 & & \\
\hline \multirow{2}{*}{ Tipo de piso } & cerâmico & cimentado & madeira & chão batido & outro & não informado & \\
\hline & 66 & 156 & 211 & 36 & 2 & 84 & \multirow{3}{*}{3322} \\
\hline Peso Aplicado & 10 & 8 & 6 & 4 & 2 & 0 & \\
\hline Sub - Total & 660 & 1248 & 1266 & 144 & 4 & 0 & \\
\hline \multirow{2}{*}{ Varanda } & $\operatorname{sim}$ & não & não informado & & & & \\
\hline & 279 & 242 & 34 & & & & \multirow{3}{*}{2790} \\
\hline Peso Aplicado & 10 & 0 & 0 & & & & \\
\hline Sub - Total & 2790 & 0 & 0 & & & & \\
\hline \multirow{2}{*}{ Conforto térmico: Treliças } & $\operatorname{sim}$ & não & não informado & & & & \\
\hline & 40 & 477 & 38 & & & & \multirow{3}{*}{400} \\
\hline Peso Aplicado & 10 & 0 & 0 & & & & \\
\hline Sub - Total & 400 & 0 & 0 & & & & \\
\hline \multirow{2}{*}{ Conforto térmico: Elemento Vazado } & $\operatorname{sim}$ & não & não informado & & & & \\
\hline & 59 & 462 & 34 & & & & \\
\hline Peso Aplicado & 10 & 0 & 0 & & & & 590 \\
\hline Sub - Total & 590 & 0 & 0 & & & & \\
\hline Confortotérmico She & $\operatorname{sim}$ & não & não informado & & & & \\
\hline Conforto termico: Shed & 17 & 502 & 36 & & & & \\
\hline Peso Aplicado & 10 & 0 & 0 & & & & 170 \\
\hline Sub - Total & 170 & 0 & 0 & & & & \\
\hline Conforto térmico-Sombrite & $\operatorname{sim}$ & não & não informado & & & & \\
\hline Conforto térmico: Sombrite & 27 & 492 & 36 & & & & \\
\hline Peso Aplicado & 10 & 0 & 0 & & & & 270 \\
\hline Sub - Total & 270 & 0 & 0 & & & & \\
\hline TOTAL & & & & & & & 25374 \\
\hline & $12 \mathrm{VAR}$ & IAVEIS & & & & & \\
\hline $\begin{array}{l}\text { IQSA MORADIAS - PADRAO CONSTRUTIV0 - } \\
\text { PONDERAC } \tilde{O} \text { O }\end{array}$ & \begin{tabular}{|l}
$555 \mathrm{EDIFI}$ \\
\end{tabular} & ICAÇÕES & & $25374 / 6$ & $/ 66600$ & & 0,381 \\
\hline & 66600 PONTO & S POSSIVEIS & & & & & \\
\hline
\end{tabular}

Fonte: Elaborada pelos autores, com base nos dados coletados em Janeiro/Fevereiro de 2013. 
MARIOSA, D. F.; GEORGES, M. R. R.; FERRAZ, R. R. N.; BENEDICTO, S. C.

Sustentabilidade socioambiental, padrão construtivo habitacional e comunidades Ribeirinhas do Tupé - Manaus, Amazonas

No conjunto das comunidades ribeirinhas estudadas ao longo do tempo, observase que a maioria das construções destina-se à residência de seus moradores. Entre as de uso coletivo, destacam-se os templos religiosos, os espaços da associação de moradores e aqueles destinados a festas, esportes e práticas culturais. Construções destinadas ao uso comercial resumem-se a bares, lanchonetes e pequenos mercados, e prédios construídos ou mantidos pelo poder público limitam-se às escolas e aos espaços auxiliares de saúde.

A maioria das construções presentes na RDS do Tupé foram edificadas usando como material estruturante unicamente a madeira ou madeira com alicerce em alvenaria; algumas poucas somente em alvenaria; enquanto que outras usaram materiais diversos como palha, casca de árvore ou lona. Ainda que do ponto de vista construtivo não seja a melhor opção em termos de estabilidade, durabilidade e resistência às agressões ambientais externas, esta preferência pela madeira resulta, entre outros fatores: da disponibilidade de matéria prima, do baixo custo relativo de sua aquisição e transporte se comparada a outros materiais estruturantes, da relativamente baixa complexidade das técnicas de construção e, especialmente, do costume local.

A cobertura das casas, ou telhamento, emprega preferencialmente materiais como fibrocimento e zinco, ótimas condutoras de calor, em detrimento da telha de barro ou palha. Como as telhas de fibrocimento e zinco estão presentes na maioria das construções na área da RDS do Tupé, estas apresentam elevado grau de desconforto térmico.

Considerando-se a relação entre o número médio de moradores por residência e o número médio de cômodos das construções, tem-se que a relação encontrada melhorou sensivelmente, de 1,212 moradores/cômodo em 2009 para 0,859 moradores/cômodo em 2013. Esta redução no nível de concentração de pessoas num mesmo espaço físico pode contribuir para, em muitos casos, reduzir a proliferação de doenças contagiosas uma vez que, dessa forma, aumenta-se a capacidade de ventilação das casas e a sensação de conforto que seus moradores podem desfrutar.

Nas construções investigadas o isolamento do solo é feito, basicamente, de madeira, que não oferece a adequada proteção contra umidade ou à entrada de insetos e pequenos animais, no caso do ripamento em madeira. A melhor opção seria o piso cerâmico, mas este é encontrado em poucas casas. Observa-se que, mesmo havendo um aumento em número absoluto de ocorrências nas comunidades ribeirinhas da RDS do Tupé, os itens de conforto térmico descritos são muito pouco utilizados. 
A comparação do desempenho em valores absolutos, por sua vez, pode levar a uma interpretação equivocada dos resultados (Figura 3). Por exemplo, na dimensão "conforto térmico", o resultado obtido na pesquisa de 2013 (1.430) é bem superior ao resultado obtido na pesquisa de 2009 (640) e esta diferença não reflete, necessariamente, um aumento na dimensão conforto térmico do desempenho dos indicadores do padrão construtivo das comunidades ribeirinhas da RDS do Tupé.

Figura 3 - Gráfico comparativo das variáveis do padrão construtivo dos anos de 2009 e 2013 (em valores absolutos)

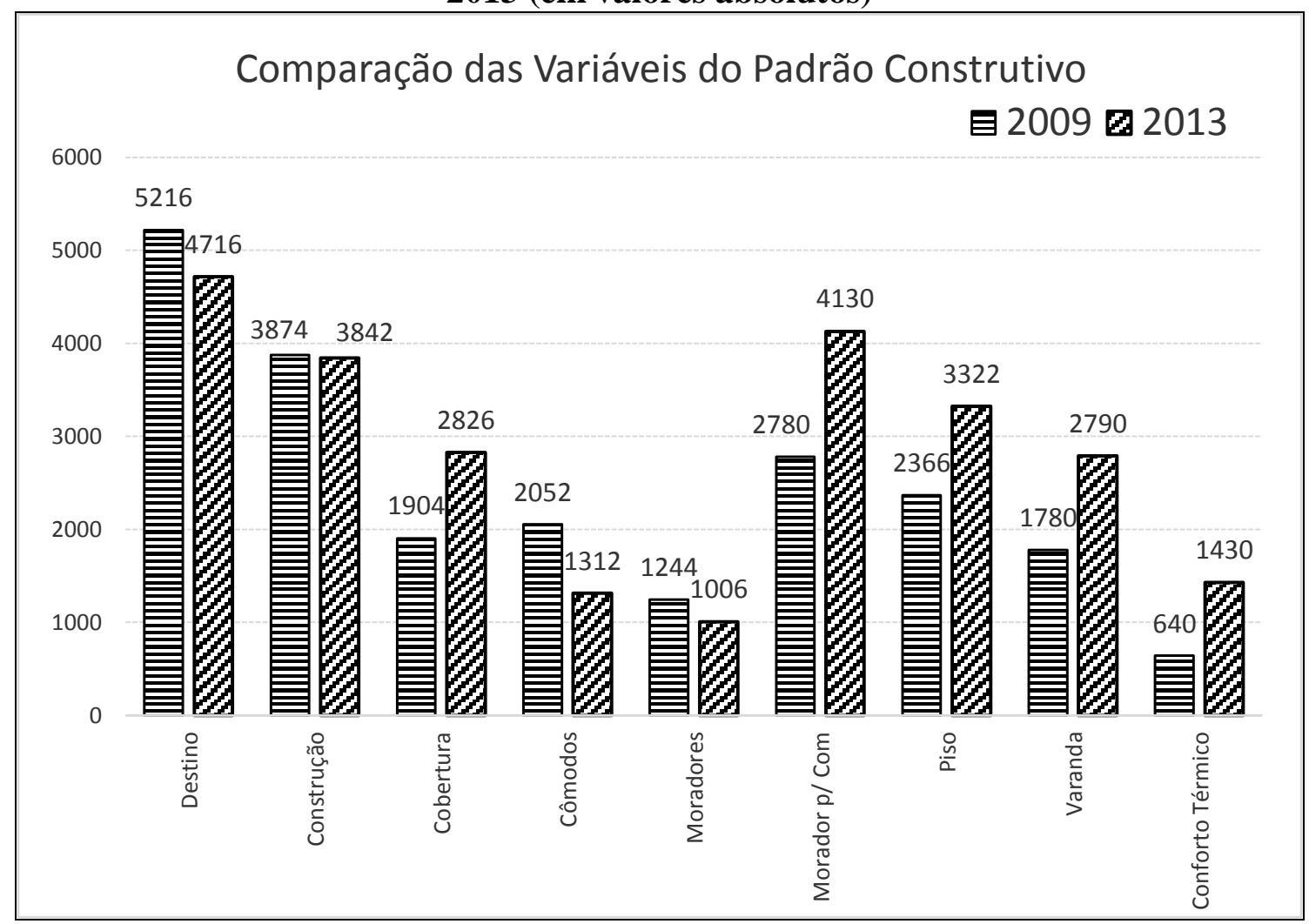

Fonte: Elaborado pelos autores, com base nos dados da pesquisa.

As disparidades observadas no resultado absoluto são explicadas pela diferença significativa no número de moradias avaliadas nas pesquisas de 2009 e 2013. Para o caso específico da dimensão "conforto térmico", na pesquisa realizada em 2009 foram coletados, em média, os dados de 315 casas, enquanto que, na pesquisa de 2013, foram 520 avaliadas. Esta diferença no número de moradias, não informadas na primeira pesquisa, resulta em valores de desempenho bem diferentes. 
MARIOSA, D. F.; GEORGES, M. R. R.; FERRAZ, R. R. N.; BENEDICTO, S. C.

Sustentabilidade socioambiental, padrão construtivo habitacional e comunidades Ribeirinhas do Tupé - Manaus, Amazonas

A partir do desempenho absoluto observado em cada ano é possível ainda extrair um índice para cada dimensão tal como é calculado o índice geral IQSA, através da divisão do desempenho absoluto observado pelo desempenho absoluto máximo possível. Sendo assim, o Quadro 2 apresenta o índice de desempenho relativo de cada dimensão para cada ano de pesquisa. As variáveis que apresentaram aumento no ano de 2013 em relação ao ano de 2009 estão destacados.

\section{Quadro 2 - Índice de desempenho por variável em cada ano pesquisado (2009 e 2013)}

\begin{tabular}{|c|c|c|c|c|c|c|c|c|c|c|}
\hline Ano & Destino & Construção & Cobertura & Cômodos & Moradores & $\begin{array}{c}\text { Morador p/ } \\
\text { Com }\end{array}$ & Piso & Varanda & $\begin{array}{c}\text { Conforto } \\
\text { Térmico }\end{array}$ & IQSA \\
\hline 2009 & 0,901 & 0,669 & 0,329 & 0,354 & 0,215 & 0,480 & 0,409 & 0,307 & 0,028 & 0,315 \\
\hline 2013 & 0,850 & 0,692 & 0,509 & 0,236 & 0,181 & 0,744 & 0,599 & 0,503 & 0,064 & 0,381 \\
\hline
\end{tabular}

Fonte: Elaborado pelos autores, com base nos dados da pesquisa de campo realizada na RDS do Tupé nos anos 2009 e 2013.

Diante do Quadro 2 observa-se que a diferença encontrada no desempenho absoluto da dimensão "conforto térmico", por exemplo, que no período analisado foi de 123,43\%, não impacta suficientemente o índice geral (IQSA) que variou, no mesmo período, 20,9\%. Isso demonstra que: se o exame do conjunto apresenta resultados diversos do exame de cada uma das partes que o compõe, a sustentabilidade socioambiental define-se mais pelo comportamento dos indicadores gerais que dos particulares. Todavia, as modificações nos parâmetros de cada variável é que permite alguma forma de planejamento e controle dos resultados no longo prazo.

As técnicas construtivas utilizadas estão mais próximas da "memória" dos construtores, delineadas pelas preferências e hábitos culturais dos moradores, do que propriamente por uma resposta às exigências do ambiente local, embora isso seja verdadeiro. Há ainda que considerar a força das técnicas corporais prevalentes no grupo social. O modo como dormem, comem e cuidam da higiene pessoal, por exemplo, interfere na escolha dos materiais construtivos, na disposição dos cômodos e no trato que dão aos dejetos e lixo doméstico produzidos.

Cultura, economia, ambiente e sociabilidade, em seu conjunto, costuram, assim, a trama das relações sociais entre as comunidades humanas e o mundo em seu entorno. Investigando-se o padrão construtivo adotado pelas comunidades reconhece-se a materialidade dessas forças sociais em operação, sua natureza, e os reflexos na qualidade de 
vida dos ocupantes de um determinado espaço ou território (ESPÍ, 2010). Neste, as construções assomam como um mundo em miniatura: o microcosmo de uma sociedade que é, para todos os efeitos, igualmente multidimensional em sua habitabilidade (NEVES; NEVES, 2006).

$\mathrm{Na}$ análise dos aspectos gerais do padrão construtivo dos edifícios encontrados nas comunidades ribeirinhas da RDS do Tupé, o fato dos resultados apontarem uma razoável melhora nos indicadores talvez não seja suficiente para as mudanças no repertório de políticas públicas, especialmente de suporte e qualificação urbanística. Investimentos na qualidade das moradias podem ajudar a reduzir índices de ocorrência de doenças infecto-contagiosas e derivadas das condições térmicas e climáticas ainda verificadas na região. O clima tropical da Amazônia apresenta altos índices pluviométricos e temperaturas elevadas durante todo o ano, de modo que as localidades necessitam de medidas específicas e pontuais, que vão além dos tradicionais mecanismos de controle epidemiológico aplicados em outras áreas de habitação, exclusivamente periféricas, rurais ou florestadas. Na RDS do Tupé, esta qualificação do habitar envolve, principalmente, a melhoria geral da qualidade do padrão construtivo, respeitando-se as exigências ambientais, sociais e econômicas envolvidas. Para isso, exige-se antes a compreensão das variáveis operativas no território e, ainda que garantida sua observância pelo texto constitucional, a disposição política para agir.

\section{CONCLUSÕES}

O presente estudo teve por objetivo examinar o emprego de indicadores de sustentabilidade socioambiental a partir da análise do padrão construtivo das casas e moradias situadas nas comunidades ribeirinhas da Reserva de Desenvolvimento Sustentável do Tupé Manaus, Amazonas (RDS do Tupé). Destaca-se que, no caso específico das comunidades ribeirinhas da RDS do Tupé, as escolhas individuais quanto ao padrão construtivo não parecem, assim, tão amplas. Quando se considera a gama de atividades possíveis de se realizar em uma área legalmente definida como "Reserva de Desenvolvimento Sustentável", a dinâmica de intervenção construtiva adquire uma perspectiva singular (AMARAL et al., 2013). 
Buscando alcançar o seu objetivo, o estudo identificou uma diversidade de componentes e variáveis que compõem o padrão construtivo habitacional na RDS do Tupé. Como indicador da sustentabilidade socioambiental considerou-se a intersecção das dimensões do econômico, sociocultural e ambiental nas comunidades ribeirinhas da RDS do Tupé. Integraram o cálculo, neste estudo, variáveis que representam o conjunto de procedimentos, técnicas e recursos construtivos que os comunitários costumam adotar em relação à estrutura física dos imóveis, sua adaptabilidade às condições climáticas e demais fatores ambientais, conforto térmico e espacial, durabilidade e resistência dos materiais empregados.

Como principal resultado deste estudo tem-se que a análise do padrão construtivo das comunidades ribeirinhas da RDS do Tupé, examinadas em escala temporal, permite a observação do comportamento das variáveis que compõem o indicador utilizado e, dessa forma, a detecção de pontos vulneráveis ou fraquezas sistêmicas que podem, se persistirem as tendências negativas encontradas ou se não alcançarem valores relativos adequados, comprometer aspectos econômicos, sociais e ambientais que caracterizam a sustentabilidade daquelas comunidades.

Dessa forma, e na perspectiva do estudo socioambiental aqui realizado, as moradias revelam a existência de um diálogo construído com o entorno, formando agregados comunitários que produzem e, ao mesmo tempo, resultam da interatividade, do modo como se desenvolve no plano histórico a relação entre os indivíduos em seu conjunto e os espaços socialmente construídos nesta dinâmica. As edificações, nesta análise, deixam de ter apenas nomes, como casas, construções ou imóveis, e passam a integrar comunidades. E se a economia, a política, a cultura e todos os demais padrões de sociabilidade que caracterizam a unidade social estruturam-se e são estruturados na interação complexa de muitos agentes, com interesses os mais diversos, na RDS do Tupé os prédios comerciais, edifícios e espaços de culto religioso, as áreas de lazer, de concentração das moradias e os espaços da produção agrícola expressam essa dinâmica social estruturando a vida coletiva.

Além de pesquisar e apontar as melhores culturas, formas de utilização e manuseio dos recursos florestais, é necessário, portanto, apreciar o alcance, limites e consequências, para o grupo, dos projetos que buscam envolvê-los em planos de manejo sustentado de recursos naturais, ecoturismo, na aplicação de técnicas inovadoras de produção e de consumo, e no desenvolvimento de novas relações econômicas, políticas e sociais sob a 
égide valorativa da preservação ambiental. Dado o caráter holístico dos problemas e a forma sistêmica utilizada para sua compreensão, a simples construção e aplicação de técnicas que permitam a revitalização econômica das comunidades locais - em outras situações exitosas talvez seja suficiente (FUKS, 2012). Afinal, constitui-se, em premissa de qualquer intervenção dessa ordem, a participação e incorporação dos sujeitos alcançados, pois que são concomitantemente agentes transformadores e sujeitos das condições socioambientais em que se acham inseridos. As atividades que envolvam possíveis e necessárias alterações nas relações entre o ambiente interno e o externo da comunidade devem ser diagnosticadas e seus efeitos corrigidos, para que alcancem os fins pretendidos, onde a construção de indicadores torna-se eficiente instrumento de apoio à gestão socioambiental (MARIOSA et al., 2014).

De outra forma, entre os principais benefícios que se pode obter do presente trabalho está a possibilidade de utilizá-lo como uma ferramenta de gestão ambiental mais efetiva dos recursos alocados em técnicas, materiais e procedimentos adotados nas edificações e, com isso, dos gastos em saúde, especialmente com o controle de vetores de doenças infecto-contagiosas e daquelas associadas à redução do conforto térmico, ventilação e vulnerabilidade às intempéries.

As principais limitações do estudo se relacionam ao fato de se utilizar para análise apenas as condições em que opera o padrão construtivo em uma área de características rurais, parcamente povoada e ambientalmente resiliente ao impacto das atividades antrópicas. Assim, como proposta para pesquisas futuras, sugere-se a continuidade dos estudos na região, especialmente relacionados à ocorrência de doenças evitáveis através da melhoria das condições de saneamento geral das comunidades e, ainda, a repetição da mesma metodologia em ambientes semelhantes.

\section{REFERÊNCIAS}

AMARAL, S. et al. Comunidades ribeirinhas como forma socioespacial de expressão urbana na Amazônia: uma tipologia para a região do Baixo Tapajós (Pará-Brasil). Revista Brasileira de Estudos de População, Rio de Janeiro, v. 30, n. 2, p. 367-399, dez. 2013.

BELLEN, H. M. Van. Indicadores de sustentabilidade: uma análise comparativa. 3. ed. Rio de Janeiro: FGV, 2008. 
BERKMAN, L. F.; KAWACHI, I.; GLYMOUR, M. Social Epidemology. New York: Oxford University Press, 2014.

BOURDIEU, P. Gosto de classe e estilo de vida. In: ORTIZ, R. Pierre Bourdieu Sociologia. São Paulo: Ática, 1983. p. 82-121.

BRAUN, R. Desenvolvimento ao ponto sustentável: novos paradigmas ambientais. Petrópolis: Vozes, 2001.

ESPÍ, M. V. El territorio desde la perspectiva ecológica. Boletín CF+ S, Madrid, n. 42/43, p. Marzo 2010.

GONÇALVES, A. Em busca do diálogo do controle social sobre o estilo de vida. In: VILARTA, R. (Org.). Qualidade de vida e políticas públicas: saúde, lazer e atividade física. Campinas: IPES Editorial, 2004.

IBGE - INSTITUTO BRASILEIRO DE GEOGRAFIA E ESTATÍSTICA. Sinopse do censo demográfico 2010. 2011. Disponível em: <http://www.ibge.gov.br/home/ estatistica/populacao/censo2010/>. Acesso em: 13 set. 2016.

JANNUZZI, P. DE M. Monitoramento e Avaliação de Programas Sociais: uma introdução aos conceitos e técnicas. Campinas - SP: Alínea, 2016.

MONTEIRO, M. I. Instrumento para coleta de dados sociodemográficos, aspectos de saúde, trabalho e estilo de vida. Texto para Discussão. Campinas: Unicamp, 2010.

NAÇÕES UNIDAS. Transformando nosso mundo: a agenda 2030 para o desenvolvimento sustentável. Rio de Janeiro: Nações Unidas no Brasil, , 2015. Disponível em:

<http://nacoesunidas.org/pos2015/agenda2030/>. Acesso em: 13 set. 2016.

NASCIMENTO, E. P. DO. Trajetória da sustentabilidade: do ambiental ao social, do social ao econômico. Estudos Avançados, São Paulo, v. 26, p. 51-64, 2012.

NEVES, C. E. B.; NEVES, F. M. O que há de complexo no mundo complexo? Niklas

Luhmann e a Teoria dos Sistemas Sociais. Sociologias, Porto Alegre, v. 8, n. 15, p. 182-207, Jan./Jun. 2006.

PEREIRA, J. C. R. Análise de dados qualitativos: estratégias metodológicas para as ciências da saúde, humanas e sociais. São Paulo: EDUSP/FAPESP, 2014.

PETERSEN, P. et al. Método de Análise Econômico-Ecológica de Agroecossistemas. 1. ed. Rio de Janeiro: AS-PTA, 2017.

SACHS, I. Sociedade, cultura e meio ambiente. Mundo \& vida, Niterói, v.2, n.1, p.7-13. 2000.

SANTOS, F. B.; MARQUES, L. A. M.; DUARTE, H. G. Direitos Fundamentais: a busca por sua efetivação. Âmbito Jurídico, Rio Grande, v. 14, n. 92, p. 01-11, 2011. 
SANTOS-SILVA, E. N.; SCUDELLER, V. V.; CAVALCANTI, M. J. (Eds.). BioTupé: meio físico, diversidade biológica e sociocultural do baixo Rio Negro, Amazônia Central. Manuas, AM: Rizoma Editorial, 2011. v. 3

SERRA, N. E. M. No ritmo das águas. Presença Revista de Educação, Cultura e Meio Ambiente, v. 6, n. 24, p. 1-13, Maio 2002.

SILVA, S. S. F. da; CÂNDIDO, G. A.; RAMALHO, A. M. C. Sistema de Indicador de Sustentabilidade Pressão-Estado-Impacto-Resposta na análise das condições ambientais resultantes dos resíduos sólidos urbanos: um estudo no Município de Cuité-PB. Qualitas Revista Eletrônica, Campina Grande, v. 13, n. 2, p. 01-16, 2012.

SILVA, S. L. da. Identidade e Complexidade: uma sociologia para os elementos emergentes da sociedade atual. Cadernos de Pesquisa Interdisciplinar em Ciências Humanas, Florianópolis, v. 1, n. 9, p. 1-14, 2000.

STELLA, R. Densidade energética: relação com variáveis demográficas, de estilo de vida, nutricionais e socioeconômicas em amostra representativa da população adulta do Município de São Paulo. 2008. 106 p. Dissertação (Mestrado) - Universidade de São Paulo, São Paulo, 2008.

WAIZBORT, L.; SIMMEL, G. sociabilidade e moderno estilo de vida. Sociabilidades, Natal, v. 2, n. 1, p. 65-69, dez. 2002.

\section{Autores}

Duarcides Ferreira Mariosa - Possui Graduação em Ciências Sociais, Mestrado e Doutorado em Sociologia, todos cursados pela Universidade Estadual de Campinas (UNICAMP). Atualmente é Docente na Pontifícia Universidade Católica de Campinas (PUC/Campinas).

Marcos Ricardo Rosa Georges - Possui Graduação em Matemática Aplicada e Computacional, Mestrado e Doutorado em Engenharia Mecânica, todos cursados pela Universidade Estadual de Campinas (UNICAMP). Atualmente é Docente no Programa de Pós-Graduação em Sustentabilidade da Pontifícia Universidade Católica de Campinas (PUC/Campinas).

Renato Ribeiro Nogueira Ferraz - Possui Graduação em Ciências Biológicas cursada pela Universidade Nove de Julho (UNINOVE), Mestrado e Doutorado em Ciências Básicas Nefrologia, ambos cursados pela Universidade Federal de São Paulo (UNIFESP). Atualmente é Docente no Programa de Pós-Graduação em Administração da Universidade Nove de Julho (UNINOVE).

Samuel Carvalho De Benedicto - Possui Graduação em Ciências Físicas e Biológicas, em Biologia e em Pedagogia cursadas pela Universidade do Estado de Minas Gerais (UEMG), e 
Graduação em Administração cursada pela Universidade Anhanguera (UNIDERP), Mestrado e doutorado em Administração pela Universidade Federal de Lavras (UFLA). Atualmente é Docente do Programa de Pós-Graduação em Sustentabilidade da Pontifícia Universidade Católica de Campinas (PUC/Campinas).

Artigo recebido em: 30 de novembro de 2016.

Artigo aceito em: 17 de junho de 2017. 